\title{
Why the numbers don't add up: A review of estimates and predictions of people displaced by environmental changes
}

\author{
François Gemenne $\mathrm{a,b}, *$ \\ a Institute for Sustainable Development and International Relations (IDDRI), Sciences Po, 27 Rue Saint Guillaume, 75337 Paris Cedex 07, France \\ ${ }^{\mathrm{b}}$ Center for Ethnic and Migration Studies (CEDEM), University of Liege, Boulevard du Rectorat 7/45, Building B31, 4000 Liege, Belgium
}

A R T I C L E I N F O

\section{Article history:}

Received 10 June 2011

Received in revised form 2 September 2011

Accepted 7 September 2011

Available online $\mathrm{xxx}$

\section{Keywords:}

Estimates

Predictions

Methods

Environmental migration

\begin{abstract}
A B S T R A C T
Estimates and predictions of people displaced by environmental changes have been highly instrumental in the ever-increasing attention given to environmental migration in the media. Yet no consensual estimate exists, let alone a commonly agreed methodology. As a result, predictions and estimates have become one of the most contentious issues in the debates on environmental migration. This article seeks to review the key estimates and predictions existing in the literature, as well as the methodologies they are built on, and the problems and caveats they are fraught with. The first part reviews the figures related to current estimates of people displaced by environmental changes, while a second part examines the predictions for future displacements. The next section synthesises the key methodological difficulties and a final section suggests some possible avenues for improvement.
\end{abstract}

(C) 2011 Elsevier Ltd. All rights reserved.

\section{Introduction}

Estimates and predictions of people displaced by environmental changes have been highly instrumental in the ever-increasing attention given to environmental migration in the media. Figures ranging from tens of million people to a billion were to be found not only in the headlines of the mainstream press, but also in official communications and research reports. The current interest for the topic is not only due to the specific nature of these migration flows, but also due to their potential magnitude.

Yet no consensual estimate exists, let alone a commonly agreed methodology. As a result, predictions and estimates have become one of the most contentious issues in the debates on environmental migration. Numerous authors have criticised the existing estimates as artificially inflated, excessively alarmist, or 'guesstimates' (Kolmannskog, 2008). Crisp notes that 'while all of the standard works on refugees are replete with numbers, few even begin to question the source or accuracy of those statistics' (1999): the remark applies to many works on environmental migration, as most of them reproduce previous statistics, without conducting any critical assessment of these data.

\footnotetext{
* Correspondence address: Institute for Sustainable Development and International Relations (IDDRI), Sciences Po, 27 Rue Saint Guillaume, 75337 Paris Cedex 07, France. Tel.: +331454976 79; fax: +331454976 85 .

E-mail addresses: Francois.Gemenne@iddri.org, F.Gemenne@ulg.ac.be.
}

This article aims to fill in this gap by presenting key estimates and predictions existing in the literature, as well as the methodologies they are built on. It was initially commissioned as a methodological review for the Foresight Project on Global Environmental Migration, a project of the UK Government Office for Science aimed at assembling and analysing the latest evidence and research on global environmental migration. ${ }^{1}$

For each estimate and prediction, the article provides an assessment of the robustness of its methodology, its predictive value, as well as its impacts in the public debates. The paper is divided into four sections: the first section reviews the estimates of people currently displaced by environmental change that exist in both the academic and grey literatures - the latter being defined as the works emanating from civil society and advocacy organisations. A second section examines the predictions that have been made regarding the number of people who could be - or would be - displaced by environmental changes in the future. These include predictions made in the past with regard to a time horizon that has since been passed. A third section synthesises some of the common difficulties, weaknesses and shortcomings of the estimates and predictions, and suggests some possible ways forward. Finally, a fourth and final section outlines some possible ways forward in order to provide more robust figures. It should be noted that the review focuses on global estimates and forecasts, and does not

\footnotetext{
${ }^{1}$ More information on the project can be found online at http://www.bis.gov.uk/ foresight/our-work/projects/current-projects/global-environmental-migration.
} 
account for figures provided with regard to a specific region or a specific event.

\section{Estimates of past and current migration flows}

There are far fewer works that attempt to count the actual number of people displaced by environmental change than works that aim to predict future migration flows. One of the most cited works on the subject, a report commissioned by UNEP in 1985 to Egyptian scholar Hassam El-Hinnawi, gave birth to the figure of 30 million of displaced people (Milan, 2004; El-Hinnawi, 1985). This figure, along with others provided by the Red Cross and environmental scientist Norman Myers, will be repeated in numerous reports and articles, sometimes inaccurately.

El-Hinnawi defined 'environmental refugees' as those people who have been forced to leave their traditional habitat, temporarily or permanently, because of a marked environmental disruption (natural and/or triggered by people) that jeopardised their existence and/or seriously affected the quality of their life (1985: 4). This very wide definition encompasses both internal and international migration, as well as temporary and permanent migration. The definition however, focuses on forced displacement, and does not address mobility as such. It addresses all types of environmental changes, and not only those induced by climate change. The definition was vividly criticised because of its large scope: amongst others, Bates notes that this definition makes no distinction between refugees who flee volcanic eruptions and those who gradually leave their homes as soil quality declines. So many people can be classified under the umbrella of 'environmental refugees' that critics question the usefulness of the concept (2002: 466).

In a 2004 interview, El-Hinnawi notes that $\mathbf{3 0}$ million people were in this situation (Milan, 2004). This number, however, is provided without a mention of the methodology used to produce it. One can therefore cast serious doubts about the robustness of the estimate and question its scientific validity. Though the number is a global estimate and doesn't distinguish between different types of environmental migration, El-Hinnawi had previously attempted to put forward a typology of environmental migration, comprising the following categories:

- Those who had been temporarily displaced because of an environmental stress (usually a natural disaster).

- Those who had to be permanently displaced and resettled in a new area.

- Finally, those who migrated within their own national boundaries because "the resource base in their original habitat (had) deteriorated to such a degree that it (could) no longer meet their basic needs' (1985: 4).

These three types of migrants no longer maintain the classical distinction between forced and voluntary migrants, thus allowing for an inflation of the numbers of so-called 'refugees'.

This estimate was followed by another one, produced three years later by Jodi Jacobsen in a paper of the WorldWatch Institute, an influential Washington-based environmental think-tank, led by environmentalist Lester Brown (Jacobson, 1988). Jacobson proposed a typology similar to that put forward by El-Hinnawi, distinguishing between temporary displacements associated with temporary environmental stress, permanent displacements associated with permanent environmental stress, and temporary or permanent displacement due to progressive environmental change (Jacobson, 1988: 5). This typology, however, was flawed by undue emphasis on the time frame of the displacement, at the expense of other important variables, such as the degree of coercion of the migration, or the distance travelled from the point of origin. There was little distinction made between forced and voluntary migration. In a fashion similar to El-Hinnawi, Jacobson vaguely defined 'environmental refugees' as 'people fleeing from environmental decline' (1988: 6). Her report identified some regions where environmental displacements were to take place, sub-Saharan Africa and coastal regions of South-East Asia in particular. She estimated the number of people displaced because of environmental reasons at $\mathbf{1 0}$ million worldwide, with more than half of this number being displaced in sub-Saharan Africa. She asserted that 'environmental refugees (had) become the single largest class of displaced persons in the world'. This figure appears to be based on the number of people who were internally displaced - whatever the reason - in the regions identified by Jacobson. A similar methodology was used by Westing in 1992: he compared the number of people being forcibly displaced worldwide, either internationally or internally, between 1986 (26.4 million people) and 1992 (41.5 million people). He then speculated that the increase of internally displaced people (IDPs) could simply be attributed to additional flows of 'environmental refugees' (Westing, 1992). If one follows Westing reasoning, this would mean that there had been $\mathbf{1 5 . 1}$ million people forcibly displaced because of environmental changes between 1986 and 1992. Those estimates were made without a serious examination of the cause of migration and attributed the rise in forced migration to a singly proxy - environmental changes.

Both El-Hinnawi's and Jacobson's reports were received with great interest by the media and civil society, but attracted harsh criticism from scholars: they had a 'short-lived shock-effect on the public debate but were rejected as unserious by scholars' (Suhrke, 1993: 6). El-Hinnawi's report had been commissioned by the UN Environment Programme, while Jacobson was a senior fellow at the WorldWatch Institute: the reports were therefore perceived as an attempt to use forced migration to draw attention to environmental problems. The estimates they provided proved instrumental in this endeavour.

The most frequently cited figure, however, comes from environmental scientist Norman Myers, who wrote several papers in the 1990s and early 2000s to alert policy-makers and public opinion about the 'growing phenomenon' represented by 'environmental refugees' (Myers, 1993, 1997, 2002; Myers and Kent, 1995). All of these papers contained estimates and predictions of the number of people displaced by environmental change. As the concept of environmental migration gained currency, they became the most influential and controversial figures discussed in public debates. To date, they remain the most elaborated estimates of environmental migration.

Myers defines 'environmental refugees' as people who can no longer gain a secure livelihood in their homelands because of drought, soil erosion, desertification, deforestation and other environmental problems, together with the associated problems of population pressures and profound poverty (Myers, 2002). Like El-Hinnawi's definition, this one also encompasses both internal and international migration, as well as temporary and permanent movement. Though the distinction between forced and voluntary migration is not explicitly stated, it appears clearly that the definition focuses on displacement rather than mobility. In his most elaborated report on the subject, Myers - along with his assistant Jennifer Kent - contended that there were in 199525 million people displaced because of environmental changes (Myers and Kent, 1995). This number appears to be based on a compilation of different regional or country reports, some of them conducted by Myers, some by other researchers. Thus the global figure of 25 million is broken down in different regions:

- 5 million in the Sahel, 'where a full 10 million had fled from recent droughts, only half returning home' (Myers, 2002);

- 7 million in other parts of Africa, seeking relief food; 
- 6 million of internal migrants in China - Myers explained that 6 million out of China's 120 million internal migrants 'could be characterised as environmental refugees', because of the shortage of agricultural plots (Myers, 2002);

- 2 million in Mexican cities - Myers (2002) added that there were one million new environmental refugees each year in Mexico;

- 1 million people who had been displaced by public works projects and remained in a refugee-like situation.

Though the addition of these different numbers falls slightly short of 25 million, Myers contended later that his estimate of 1995 was 'cautious and conservative' (Myers, 2002). This estimate warrants some observations:

- First, the estimate doesn't describe a flow, but a stock: people who have been displaced because of environmental factors but have returned or resettled elsewhere are not included in the count.

- Second, the estimate does not distinguish between different types of environmental changes as migration drivers, and includes development projects amongst these.

- Finally, the estimate is based on other works, whose methodologies have not been described, but are unlikely to be similar - this casts serious doubts about the scientific accuracy of the estimate.

Overall, Myers' estimate of the number of 'environmental refugees' does not rely on any specific methodology: for each region of the world, the number of internally displaced people is considered. On the basis of these figures, Myers makes an estimate of the proportion that could have been displaced because of environmental disruptions. This estimate is based on reports and observations of environmental degradation in the considered region, but no attention is given to an examination of the linkages between environmental change and migration behaviour. In an essentialist fashion, Myers assumes that all people displaced in an area affected by environmental changes have been displaced solely because of these changes. Another interesting point to consider is that Myers rules out the possibility that some could have been displaced outside of their country - international migration is not considered in his estimate.

Despite these limitations, the figure of 25 million made a lasting impact in the public debates, and was picked up in a number of reports and documents aimed at raising awareness about the plight of 'environmental refugees'. Simms and Conisbee, for example, made ample use of the figure in an advocacy report requesting that people displaced by environmental changes be granted a refugee status (Conisbee and Simms, 2003). The credibility of the figure was reinforced after the Red Cross stressed in its 2001 World Disasters Report that more people were forced to leave their homes because of environmental disasters than war (International Federation of Red Cross and Red Crescent Societies, 2001). This claim was based on operational reports from the Red Cross activities in the field. The figure of 25 million was also quoted in the famously controversial report of the NGO Christian Aid, "Human Tide' (Christian Aid, 2007). In this latest report however, the figure is not taken from Myers, but rather from a factsheet issued in 2006 by UNHCR with regard to internally displaced people (IDPs). After careful examination of the source, it appears that the number of 25 million people relates to the number of IDPs worldwide, and not to the number of people displaced because of environmental change. It therefore appears that the UNHCR factsheet has been misquoted in the Christian Aid report. Notwithstanding this mistake, the report asserts that there are currently 163 million people forcibly displaced worldwide. Amongst these people are 25 million displaced by natural disasters, as stated above, but also 105 million people displaced by development projects. This figure is solely based on an interview with Prof. M. Cernea, a specialist of population displacements induced by development projects.

Finally, in an interview with the Guardian and a related press briefing, Prof. J. Bogardi, then Director of the Institute for the Environment and Human Security of the United Nations University (UNU-EHS, Bonn), claimed that there were 10 million people displaced every year because of environmental deterioration (Adam, 2005). This figure doesn't seem related to any empirical study or statistical information, but appears to be derived from the projection, made in the same interview, that there would be 50 million 'environmental refugees' by 2010 . Given that the interview was made in 2005, one can assume that Prof. Bogardi made the calculation that 10 million people needed to be displaced every year in order to reach the number of 50 million by 2010. In any case, this figure seems to have been provided for the sole purpose of feeding the media appetite for numbers.

At this stage, it seems relevant to consider also how the literature on migration at large has addressed this issue. Piguet (2009) rightly recalls that environmental conditions were initially considered as factors that drove people to migrate in the works of the pioneers of migration studies, before being overshadowed by economic and political factors and eventually forgotten. Only a few, more recent works, such as those of Hunter (2005) or Henry and Piché (2004), address environmental migration as part of broader migration dynamics. Piguet makes the case for the environment to be 're-embedded' into migration theories and models. Though it has indeed been little considered in most migration models, it is worth noting that some authors have proposed alternative methodologies to measure environmental migration, some of them directly inspired by demographical or geographical measurements of migration. Afifi and Warner (2008) proposed to use a gravity model, directly inspired by push-pull theories of migration. The model integrated different migration variables, both environmental and non-environmental, such as land degradation or the occurrence of floods, but also the distance between countries or the GDP per capita. The model per se was not able to produce any estimate or prediction, but controlling for nonenvironmental variables allowed the authors to conclude that environmental factors had a significant impact on migration flows between countries. A major caveat of the model was however that it applied only to international migration and thus proved shortlived, since it had long been established that environmental migration is generally restricted to internal movement (Boano et al., 2008; Jäger et al., 2009).

Scholars from the University of Sussex have also suggested that methods borrowed from demographic and geographic studies on migration could prove insightful for estimating and predicting the number of people displaced by environmental change, such as agent-based modelling (Kniveton et al., 2008). Agent-based modelling is a method that simulates the behaviours and responses of actors to stimuli, in this case environmental change, as well as the interactions between these different actors. Though the method has been sporadically applied in some case-studies, no global estimate or prediction has been conducted yet.

Finally, estimates on the number of people displaced by catastrophic events such as natural disasters seem more robust and less controversial. The latest and most accurate study is the one released in June 2011 by the Internal Displacement Monitoring Center and the Norwegian Refugee Council (Yenotani, 2011). The study reviews comprehensively the natural hazard-induced disasters that occurred in 2009 and 2010, and concludes that 17 million people were displaced by such disasters in 2009, and $\mathbf{4 2}$ million in 2010, most of them in Asia. These numbers have not attracted controversy so far, and rely on a simple, four-pronged 
methodology: first, a baseline of events is identified, thanks to the EM-DAT database. ${ }^{2}$ Then some events are prioritised - those where more than 50,000 people were affected - in order to create a core dataset. For each event, data is collected from various and organisations about the number of displaced people. An estimate of total displacement is then made for each event, and the numbers are analysed.

Other estimates of people displaced by natural disasters have also been conducted in the past by various organisations, including the Federation of Red Cross and Red Crescent Societies or the UN Office for the Coordination of Humanitarian Affairs (OCHA). These reports have been relatively consensual, as they all rely on a similar methodology - indeed, the key methodological challenges and caveats lie with slow-onset environmental changes.

\section{Predictions and forecasts of future migration flows}

Many of the authors who had provided estimates of current and past numbers of people displaced by environmental change also provided forecasts for future displacements, at different time horizons. Most of the predictions were affected by the same flaws and biases as were current estimates: a weak or inexistent methodology, and a tendency to use the numbers in order to raise awareness.

In line with his current estimate, El-Hinnawi warned that 'this number (would) increase with deteriorating environmental and economic conditions in parts of the developing world' (Milan, 2004). One can therefore assume that the predictions also incorporate, at least partly, people displaced because of economic conditions. In 1989, UNEP Executive Director Mostafa K. Tolba echoed these figures, and warned that 'as many as 50 million people could become environmental refugees' by 2010 (Tolba, 1989). The forecast was also reinstated later by then UNEP Executive Director Klaus Töpfer ${ }^{3}$ in numerous statements and interviews, which gave the figure a certain prominence in public debates over the issue. In early 2011, different blogs and internet websites noted that the ' 50 million refugees' had failed to materialise, which gave rise to a controversy documented in an article by The New Scientist (Pearce, 2011). But even more than the figure of 50 million, it is a forecast of 150 million people displaced by 2050 that captured the public's attention.

The figure was mentioned by Myers, outlining the methodology that allowed him to come up with the forecast (Myers and Kent, 1995; Myers, 2002). Myers also cited El-Hinnawi's and UNEP's estimates, though it is not clear whether he used these numbers and added a methodological apparatus or whether he used ElHinnawi's methodology and came up with the same conclusions. In any case, Myers contended that the rise was mostly the result of three concomitant and interrelated factors: environmental decline, spreading poverty and demographic expansion (Myers, 2002). According to Myers, the two latter problems were directly related to the first one. It appears therefore that the projections forecast not only the people who would be displaced solely because of environmental changes, but also the people displaced for other reasons, though these reasons would be linked to environmental factors. The rise from 25 million 'environmental refugees' in 1995 to $\mathbf{5 0}$ million in $\mathbf{2 0 1 0}$ can easily be explained by the fact that such displacements started in 1980, according to Myers. He concludes that at least the same number of people would be displaced between 1995 and 2010 than between 1980 and 1995. The forecast of 150 million displacees by $\mathbf{2 0 5 0}$ takes into account the demographic expansion of developing countries as well as the

\footnotetext{
2 The EM-DAT database, hosted in the University of Louvain (Belgium), is widely considered as the most comprehensive public database of natural disasters.

${ }^{3} \mathrm{Mr}$ Töpfer's term as Executive Director of UNEP was 1998-2006.
}

deteriorating environmental conditions. Amongst these, Myers considers principally sea-level rise and desertification. His forecast is based on the number of people that are expected to live in the regions at risk by 2050: in a deterministic manner, Myers assumes that all these people will be forced to leave.

Contrary to a widely held belief, this figure has never been reproduced in the Assessment Reports of the Intergovernmental Panel on Climate Change (IPCC). It has been picked up, however, in another report on climate change that received high media exposure: the Stern Review on the Economics of Climate Change (Stern, 2007). The review, however, notes cautiously that the estimate has not been rigorously tested, but it remains in line with the evidence presented throughout this chapter that climate change will lead to hundreds of millions more people without sufficient water or food to survive or threatened by dangerous floods and increased disease'.

In a subsequent paper, Myers updated his 2050 prediction, and warned that when global warming takes hold, 'there could be as many as 200 million people ${ }^{4}$ overtaken by sea-level rise and coastal flooding, by disruption of monsoon systems and other rainfall regimes, and by droughts of unprecedented severity and duration' (Myers, 2002). The people at risk of flooding would be distributed as follows:

- Bangladesh: 26 million

- Egypt: 12 million

- China: 73 million

- India: 20 million

- Other parts of the world, including small island states: 31 million.

In addition to these 162 million people, Myers warns that at least 50 million are at risk because of droughts and other climate dislocations.

Through frequent repetitions, and despite its highly speculative nature and questionable scientific accuracy, this latest figure of 200 million people displaced by 2050 has been taken as empirical evidence, and has been frequently cited in media reports and other studies. Such reports and studies include works and communications by the UNU-EHS (Renaud et al., 2007), Friends of the Earth (Friends of the Earth Australia, 2007) or the Geneva-based Global Humanitarian Forum (Global Humanitarian Forum, 2009). These works garnered large attention, especially in the run-up to the 2009 Copenhagen Conference, contributing to the spreading of the forecast in public debates.

Myers can certainly be credited with drawing worldwide attention to the topic of environmental migration. However, his work is largely based on speculative common sense rather than on actual figures and estimates - a point that has been vigorously criticised by many scholars, including Black (2001) and Castles (2002).

Another highly controversial estimate came from the abovementioned Christian Aid report (Christian Aid, 2007), which predicted that as many as one billion people could be forcibly displaced by 2050 . Out of these 1 billion people, the report predicted that $\mathbf{3 0 0}$ million would be directly displaced as a result of environmental disruptions:

- 50 million people displaced by natural disasters, at a rate of 1 million people displaced per year;

- 250 million people permanently displaced because of climatechange related phenomena such as droughts, famines, floods and hurricanes.

This last figure is based on an interview with Prof. N. Myers, reflecting upon his previous estimates. In addition, the report mentions that 645 million people will be displaced as a result of

\footnotetext{
${ }^{4}$ Bold fonts were added by the author of this review.
} 
development projects, at a rate of 15 million a year, and concludes that 'without urgent action, climate change will make the forced displacement crisis the biggest threat facing developing countries over the next 50 years'. The report by Christian Aid attracted considerable media attention, but was harshly rebuffed by the scholarly community as unserious and overly alarmist.

Biermann and Boas (2010) also sought to predict the numbers and origins of 'climate refugees', recognising that 'all current predictions are fraught with numerous methodological problems and caveats'. In order to circumvent these difficulties, they attempt to distinguish the number of people affected by different climate impacts (extreme weather events, sea-level rise, drought and water stress) in different regions of the world. In order to do this, they use different studies assessing the number of people at risk of these impacts, and conclude prudently that the total number of people at risk of becoming climate refugees by 2050 could well be around or over $\mathbf{2 0 0}$ million (...)'. A key caveat of this assessment, though the authors admit it's only a rough estimate, is that it is based on secondary sources - including the works of Myers whose methodologies are not consistent with each other. Despite this caveat, the paper appears more robust than its predecessors, because it attempts to break down this global 200 million figure by regions and climate change impacts. In particular, the authors calculated the number of people who would be affected each year by 2080s by storm surges with a sea-level rise of about $38 \mathrm{~cm}$ in different regions. Though this sea-level rise could be disputed for being underestimated (Rahmstorf, 2010), they came up with the figure of 82 million people affected in Africa, 141 million for Asia, and 2.5 million for small island states. Interestingly, they departed from the often-assumed deterministic perspective and calculated how these numbers could be reduced thanks to evolving protection mechanisms. In that case, the numbers would 14 million for Africa, 76 million for Asia and 1.2 million for small island states. For each continent, they provided examples of estimated displacement induced by sea-level rise, including 12 million 'climate refugees' in Egypt, 26 million in Bangladesh, 73 million in China and 20 million in India, all by the year 2050. They repeated the exercise with other climate impacts such as tropical cyclones and water stress, but provided figures that were considerably less detailed. For example, people at risk of water stress in Africa by 2085 due to a temperature increase of $2-3{ }^{\circ} \mathrm{C}$, depending on population level, were estimated to be between 197 million and 1.65 billion - an eightfold variation.

More recently, a number of studies of studies discussed the possible effects of climate change in the event when temperature increase would reach $4{ }^{\circ} \mathrm{C}+$ by the end of the century. In that case, Nicholls et al. (2011) stated that up to $\mathbf{1 8 7}$ million people could be forcibly displaced because of sea-level rise over the century. This figure is characterised by an excessive deterministic bias, as the it reflects the number of people at risk of coastal flooding but does not take into account other factors that will weigh upon migration behaviours, such as adaptation strategies or poverty.
Figures that forecast the number of people who could be at risk because of the adverse effects of climate change but did not discuss their eventual displacement proved far less controversial. Nicholls predicted that up to $\mathbf{3 0}$ million people a year could be at risk of coastal flooding because of sea-level rise by 2080 (Nicholls, 2004), while the Secretariat of the United Nations Convention to Combat Desertification (UNCCD) warned that $\mathbf{1 3 5}$ million people were at risk of being displaced because of desertification by 2030, with 60 million people expected to move from sub-Saharan Africa to Northern Africa and Europe (United Nations Convention to Combat Desertification, 2010).

These different forecasts share some common characteristics: in particular, they were received with great scepticism in the scholarly community, and great interest in the media and policy-making community. Thus, at the same time that they were facing harsh criticism, they also made a significant impact in public debates, as whistle-blowers of an upcoming humanitarian catastrophe. The media appetite for numbers is well known: 'startling statistics shape our thinking about social issues' and define the importance and seriousness of these issues (Best, 2001). Forecasts of 'environmental refugees' perfectly fit that bill, and indicated an issue of tremendous magnitude and importance. Doing so, they also shaped how the public and policy-makers would think about the issue.

Most of these forecasts were published in the grey literature, which might explain why little attention was devoted to methodological issues. Only a few reports were published in academic journals, meaning that the methodology of most works was never reviewed externally.

Finally, most forecasts use the same timeframes for the estimates and predictions: 2010 and 2050. The choice of these timeframes has been heavily influenced by the timeframes used by the IPCC for its Assessment Reports - and indeed, the forecasts depend heavily upon climate change projections. We are now in 2011 , one year after the year that was usually chosen as the first year of reference for the forecasts. Thus it would seem relatively easy to check the validity of these forecasts against reality. Unfortunately, in the absence of any statistical information, it is currently impossible to assess the accuracy of these predictions against empirical realities. Furthermore, the absence of a consensual definition of 'environmental migration' means that different numbers can refer to different realities - this definitional problem will be addressed in the next section.

Table 1 synthesises the principal and comparable figures provided in the different estimates and forecasts.

\section{Difficulties and obstacles}

Predictions and estimates remain one of the most contentious issues in public debates on environmental migration. Many scholars suspect that these figures lack any empirical basis, and are put forward with the sole purpose of raising awareness and garnering media attention around the issue of climate change, or

Table 1

Estimates and forecasts of the number of people displaced by environmental changes.

\begin{tabular}{|c|c|c|c|}
\hline Source & Estimates at the time of publication of the report & Predictions by 2010 & Predictions by 2050 \\
\hline UNEP (Tolba, 1989; Milan, 2004) & 30 million & 50 million & - \\
\hline Jacobson (1988) & 10 million & - & - \\
\hline Myers $(1993,2002)$ & 25 million & - & 150, then 200 million \\
\hline Myers and Kent (1995) & 25 million & 50 million & 212 million \\
\hline Red Cross (2001) & More than people displaced by war & - & - \\
\hline UNU-EHS (Adam 2005; Renaud et al., 2007) & 10 million/year & 50 million & 200 million \\
\hline Stern (2007) & - & - & $150-200$ million \\
\hline Christian Aid (2007) & 25 million & - & 300 million \\
\hline Biermann and Boas (2010) & - & - & 200 million \\
\hline
\end{tabular}


environmental degradation at large. Yet the figures are important, as they are often requested by policy-makers in order to assess the importance of the phenomenon and develop policy responses. The role of science and statistics in the policy process has been widely documented in the literature (Sabatier, 1987; Majone, 1989). Predictions and estimates have been abundantly used to advocate for the development of new policies and mechanisms of protection to assist the people displaced by environmental changes. Yet whereas back-of-the-envelope figure can suffice to generate public awareness, the design and funding of appropriate policy responses will often require more detailed and robust figures.

Despite their flaws and biases, predictions and estimates made a lasting impact in both policy and scholarly debates: they are now often quoted as scientific truth, without any questioning of the methodology used. The multi-causality of displacement, as well as the confusion between forced and voluntary migration, make it difficult to identify a precise and rigorous number of environmentally displaced persons. Given the lack of comprehensive methodology and empirical studies, the field is wide open for guesses and doom-laden estimates rather than actual numbers.

Different factors impede upon the collection and development of accurate data and forecasts. Some of these factors are common to all displacement-related issues; others are specific to environmental migration.

First, the quest for numbers is hampered by the debates on controversies over the concept and very definition of environmental migration. Without clear definition, providing accurate data seems a daunting task. As noted by Biermann and Boas (2010), 'all studies operate with different terminology and definitions, which makes it difficult to compare results'. Different problems impede upon the search for a common definition, including tensions between scholars who would like to establish 'environmental migration' as a distinct migration category and scholars who insist on the multi-causality of migration, as well as tensions between international agencies over the perimeter of their respective mandates (Dun and Gemenne, 2008). It is worth noting, however, that a similar problem is encountered when counting refugees, even though a legal definition exists. In the words of Crisp, 'any form of enumeration exercise must be based upon a clearly defined unit of measurement if it is to produce reliable, usable and comparable data. In the case of refugee statistics, however, such clarity does not always exist' (1999).

Most of displacements triggered by environmental factors are intra-national, rather than international. This poses a further statistical problem, since counting internal movements is much more difficult than cross-border movements: 'the machinery to collect data on these movements simply does not yet exist' (Brown, 2008). Crisp provides a list of questions that are left unanswered when one is attempting to count internally displaced people (IDPs):

In the absence of a clear criterion such as the crossing of an international border, how far does a person have to move to be considered 'internally displaced'? When do internally (displaced) people cease to warrant that status: when they return to their original place of residence, or when they have achieved a certain degree of physical and socio-economic security in the place to which they have fled? Given that a large proportion of the world's IDPs are thought to live in towns and cities, how can they be differentiated from other rural-to-urban migrants? (1999)

Some further problems are specific to the nature of environmental migration. When it comes to predictions, figures are usually based on the number of people living in regions at risk, and not on the number of people actually expected to migrate. Estimates do not account for adaptation strategies, nor different levels of vulnerability to change. This confusion between the number of people living in affected regions and the number of migrants is rooted in a deterministic perspective, and is a key reason for the inflation of numbers.

Predictions also need to take into account demographic changes that are expected to occur over the next decades. Whereas the global population growth can be predicted to a certain extent, its geographic distribution remains uncertain. In recent years, migration to urban areas has accelerated. An increasing number of people live in regions highly exposed to natural risks and hazards, resulting in an increased number of disasters. These demographic shifts are particularly significant in developing countries, and they make estimates of potential migrants a difficult task.

Also, it is expected that a large number of future displacements will be induced by the impacts of climate change. It is possible to mitigate these impacts through adaptation strategies, and to mitigate climate change itself by reducing our greenhouse gas emissions. Thus the future impacts of climate change on societies will greatly depend on future levels of greenhouse gas emissions, as well as on the adaptation strategies that will be implemented in vulnerable regions. Some impacts can be avoided through significant emissions cuts, while adaptation strategies can help populations cope with the impacts that cannot be avoided. In a nutshell, future displacements depend to a large extent upon the climate policies that are implemented today. Because of the inertia of the climate system, the impacts of global warming until 2050 are largely pre-determined by our past emissions (Hansen et al., 2006). Impacts beyond 2050 depend heavily on our current emissions, and this is the reason why only few predictions go beyond 2050 . Though the impacts of climate change until 2050 are largely known, thanks to the IPCC reports, adaptation strategies can minimise how these impact affect societies. Hence future displacements also depend, to a great extent, upon the adaptation strategies that are implemented today - and pro-active migration might actually be part of them. Overall, public policies play a great role in shaping migration dynamics (Zolberg, 1989). With regard to environmental changes, they might encourage or deter movement, or provide adaptation schemes that will sustain people's livelihoods in their region of origin. Yet the role of public policies - be they environmental or migration policies, or both - is often unaccounted for in the estimates and forecasts.

Finally, the importance of timeframes is of crucial importance: do the predicted numbers describe an accumulation of migration flows over a certain period of time, or do they account for a stock of environmental migrants at a certain period of time? Are those who have been able to return home included in the predictions or not? Though these questions are of crucial importance, they are rarely addressed and fuel the suspicion that the numbers are artificially inflated.

Despite these difficulties, getting the numbers rights is an important step for developing adequate policies. The programming of assistance and mobilisation of resources, including funding, depends on accurate numbers (Crisp, 1999). In the absence of reliable statistics, numbers can be easily inflated and manipulated, in order to attract attention on some populations, sometimes at the expense of other populations in need of protection.

\section{Ways forward}

In order to move forward, three different avenues could be explored. First, a right framework for research needs to be set. This implies the design of a common working definition, as well as the development of statistical systems and local research capacities. Second, quantitative research in the field needs to be rescaled, both with regard to their timeframe and their spatial dimension. Third 
and last, new methods and techniques have to be tested, such as longitudinal studies, scenarios, or agent-based modelling. The following paragraphs detail a few suggestions along these three avenues, which could pave the way towards more accurate estimates and projections.

\subsection{Setting the right framework for research}

First, the definitional issue seems paramount. As pointed by Suhrke, 'broad categorizations invite large numbers' (Suhrke, 1993): many figures rely on very broad, loosed definition of 'environmental migration', in order to encompass as many people as possible. International organisations and agencies also use different definitions and terminologies, reflecting the perimeter of their mandate. These different definitions and typologies make estimates and projections hardly comparable, and any attempt to come up with more robust figures will be hampered by this definitional issue. A high-level group comprised of scholars and representatives from international organisations could be tasked with providing a working definition and typology that would become a referential. The definition would need to distinguish between forced and voluntary movement, as current figures often confuse these two types of migration, though they reflect reactions to environmental changes that are fundamentally different from each other. Though the line between forced and voluntary migration has become increasingly blurred in recent years and both can hardly be defined as clear-cut categories (Hugo, 1996), figures should state more clearly whether they consider forced or voluntary movements, or both. A common typology would be most helpful for this.

Statistical systems also need to be further developed. Many developing countries simply don't have the capacity to monitor migration flows, especially within their own borders. The development of country profiles could be a first step in this endeavour, which will require significant resources and capacitybuilding. The inclusion of questions related to the perception of environmental changes and internal mobility in national surveys and census would another major step in this direction.

Research on environmental migration is mostly conducted from industrialised countries. Yet most of these movements take place in developing countries, where local expertise is insufficiently mobilised. Too many estimates and predictions are produced without any supporting evidence from empirical studies. Quantitative research needs to be complemented with and tested against qualitative research, and local research capacities urgently need to be developed. The setting up of local observatories, for example, could provide a monitoring of environmental migration in the long-run.

\subsection{Rescaling estimates and predictions}

Despite a few exceptions, estimates and predictions tend to be produced on the global level. As a result, they often have little policy relevance, as they aggregate different types of movement, requiring different types of policy intervention. Boano et al. suggest that, instead of drafting global estimates, 'a more valuable route to understanding the potential scale of displacement, and thus the scope of policy intervention', would consist in getting a more nuanced understanding of the different forms of environmental migration, and developing a much more empirically grounded approach to the issue (2008). They suggest that research should focus on the identification and mapping of potential environmental 'hotspots', the monitoring of changing conditions, the examination of 'tipping points' and the tracking of migration trends. Kniveton et al. concur that a first step is to 'try to understand how people cope with the different types of gradual stresses and sudden shocks brought about by climate change and variability' (2008). As a matter of fact, the most robust quantitative studies so far were conducted on the local or national level. They include the works of Massey et al. in Nepal (2007) or the works of Henry et al. in Burkina Faso $(2003 ; 2004)$. Studies that focus on the local level allow for a crisper understanding of migration behaviour and a more accurate measurement of migration trends. In the current state of our understanding of environmental migration, it is probably impossible to provide a reliable and accurate global estimate.

Another scaling issue concerns the timeframe of estimates and predictions, which is often unclear: for example, when one states that there will be 150 million 'environmental refugees' by 2050 , does that mean that 150 million people will be displaced between now and 2050, or that 150 million people will be displaced in the year 2050? What about the migrants who will return to their place of origin? Does one speak about permanent or temporary migration? More clarity is needed with regard to the timescales that are used.

Finally, another rescaling effort is needed with regard to the expected magnitude of climate change. Most forecasts are based on the assumption that global warming will be limited to $2{ }^{\circ} \mathrm{C}$ over the course of the century, which is the official objective adopted during the Copenhagen and Cancún conferences, in 2009 and 2010 respectively. Yet many scientists and observers believe that this objective will not be achieved, and that average global temperature increase is likely to be around $4{ }^{\circ} \mathrm{C}$ by the end of the century (Betts et al., 2011). A $4{ }^{\circ} \mathrm{C}$ temperature rise could increase migration flows in some places, but could also limit migration possibilities for some populations (Gemenne, 2011). Predictions should be rescaled in order to account for the possibility of a $4{ }^{\circ} \mathrm{C}$ temperature rise by the end of the century, which appears as a possibility that ought to be considered seriously, given the current commitments to reduced greenhouse gas emissions. Predictions also tend to confuse the movements that could be induced by climate change impacts and other environmental disruptions such as natural disasters. More effort should be made in order to identify the additional migration volumes that can be attributed to different types of environmental changes: this would allow to assess the relative weight of global warming on migration trends over time.

\subsection{Exploring new methods}

Piguet has conducted a useful review of the different methods that could be used in order to measure environmental migration (2010). While some methods tend to be frequently used, others have been little explored, despite promising prospects.

Kniveton et al. (2008) suggest that agent-based modelling should be used to simulate future migration patterns on the basis of current migration behaviours. An agent-based model is a computational model that simulates the behaviours of agents in reaction to some stimuli. The model has been successfully used to study migration trends, but has not yet been applied to environmental migration. Though the method remains quite controversial, it could provide valuable insights for the prediction of future flows of environmental migration.

Multi-level analysis has been little used as well, though this method is widely recognised as one of the most robust methods, as it combines different methods on different levels, including household surveys and time series. This allows for the monitoring of migration trends over longer periods of time: current studies of environmental migration are usually snapshots that fail to capture long-term migration dynamics. As environmental changes are often incremental over time, it is essential to track migration trends over longer periods of time. Multi-level analysis should thus be used more frequently than it has been so far, whenever possible. 
An example of such studies include the works of Henry et al. in Burkina Faso (2003; 2004), which tracked the migration behaviours of thousands of households over several years and crosschecked them against longitudinal environmental data.

Finally, the speculative character of predictions needs to be acknowledged. A way to remedy this problem is to resort to different possible evolution scenarios.

The EACH-FOR project ('Environmental Changes and Forced Migration Scenarios', www.each-for.eu) developed such a modelling exercise, based on scenarios relating to different policy directions (Jäger et al., 2009). The exercise provides some ways forward in order to take into account the different variables that will impact upon the number of people displaced by environmental changes. However, in order to provide robust scenarios, one needs to be provided with consistent statistical indicators, which are absent in most developing countries. The EACH-FOR scenarios were only realised for a limited number of countries, and without robust quantitative data. In that sense, they need to be recognised as a methodological exercise rather than an accurate projection of the people who could be displaced by environmental change. They highlight, however, the need to better take into account the role of public policies as a determining condition of the nature and magnitude of future displacements and migration. As mentioned earlier, most forecasts and predictions ignore completely the role of public policies in the generation of environmental migration.

\section{Conclusion}

As they stand today, estimates and predictions regarding environmental displacement are not satisfactory. Many of them appear to have been put forward in order to generate media attention rather than to provide empirically grounded estimates and predictions. In particular, they lack robust methodological foundations, and are generally grounded in a deterministic perspective, assuming that all people impacted by environmental changes will move away from their homes. Furthermore, they are strongly biased towards climate change, often at the expense of other environmental changes. Overall, it seems that a key methodological debate relies on the relative weight of environmental factors amongst the various drivers of migration. Since early on, scholars have been divided between minimalists and maximalists (Suhrke, 1994), the latter assuming that environmental change is a major driver of migration and displacement, whereas the former tend to insist on the multi-causality of migration. As of today, this debate remains extremely fierce.

Yet it seems difficult, at the moment, to provide more accurate data. Many developing countries lack the statistical capacity to monitor migration movements. In the absence of commonly agreed definition, robust empirical studies and a statistical apparatus, it seems difficult to envision how accurate data could be provided. This doesn't mean however that we should abandon the idea of building quantitative data, as these are of central importance for the development of policy responses. Current estimates and forecasts need to be rescaled on different levels, and innovative methods such as scenarios, multi-level analysis or agent-based modelling can provide some interesting ways forward. This will require however that the current quest for global figures is abandoned, in order to make way for more focused studies, as these could provide numbers that would be policyrelevant and yet scientifically sound.

\section{Acknowledgements}

This article has been commissioned as part of the Foresight Project on Global Environmental Migration. The author is grateful to the project's team for support and advice, as well as to two anonymous reviewers for very helpful and insightful comments.

\section{References}

Adam, D., 2005. 50 m Environmental Refugees by End of Decade, UN Warns. The Guardian, London.

Afifi, T., Warner, K., 2008. The Impact of Environmental Degradation on Migration Flows across Countries. Working Paper No. 5. UNU-EHS, Bonn.

Bates, D.C., 2002. Environmental Refugees? Classifying Human Migrations Caused by Environmental Change. Population and Environment 23 (5), 465-477.

Best, J., 2001. Damned Lies and Statistics. Untangling Numbers from the Media Politicans, and Activists. University of California Press, Berkeley and Los Angeles.

Betts, R.A., Collins, M., et al., 2011. When could global warming reach $4{ }^{\circ} \mathrm{C}$ ? Philosophical Transactions of the Royal Society A 369 (1934), 67-84.

Biermann, F., Boas, I., 2010. Preparing for a warmer world. Towards a global governance system to protect climate refugees. Global Environmental Politics $10(1), 60-88$.

Black, R., 2001. Environmental refugees: myth or reality? New Issues in Refugee Research, No. 34. UNHCR, Geneva.

Boano, C., Zetter, R., et al., 2008. Environmentally displaced people: understanding the linkages between environmental change, livelihoods and forced migration. Forced Migration Policy Briefing. Refugee Studies Centre, Oxford.

Brown, O., 2008. Migration and climate change. IOM Migration Research Series, No. 31. IOM, Geneva.

Castles, S., 2002. Environmental change and forced migration: making sense of the debate. New Issues in Refugee Research, No. 70. United Nations High Commissioner for Refugees, Geneva.

Christian Aid, 2007. Human Tide: The Real Migration Crisis. Christian Aid, London.

Conisbee, M., Simms, A., 2003. Environmental Refugees. The Case for Recognition. New Economics Foundation, London.

Crisp, J., 1999. Who has counted the refugees? UNHCR and the politics of numbers. New Issues in Refugee Research, No. 12. UNHCR, Geneva.

Dun, O., Gemenne, F., 2008. Defining 'environmental migration'. Forced Migration Review 31, 10-11.

El-Hinnawi, E., 1985. Environmental Refugees. UNEP, Nairobi.

Friends of the Earth Australia, 2007. A Citizen's Guide to Climate Refugees. Friends of the Earth Australia, Fitzroy, Australia.

Gemenne, F., 2011. Climate-induced population displacements in a $4{ }^{\circ} \mathrm{C}+$ world. Philosophical Transactions of the Royal Society A 369 (1934), 182-195.

Global Humanitarian Forum, 2009. The Anatomy of A Silent Crisis. Global Humanitarian Forum, Geneva.

Hansen, J., Sato, M., et al., 2006. Global temperature change. Proceedings of the National Academy of Sciences 103 (39), 14288-14293.

Henry, S., Boyle, P., et al., 2003. Modelling the influence of the natural environment on inter-provincial migration in Burkina Faso, West Africa. Applied Geography 23 (115-136).

Henry, S., Piché, V., et al., 2004. Descriptive analysis of the individual migratory pathways according to environmental typologies. Population and Environment 25 (5), 397-422.

Hugo, G., 1996. Environmental concerns and international migration. International Migration Review 30 (1), 105-131.

Hunter, L., 2005. Migration and environmental hazards. Population and Environment 26 (4), 273-302.

International Federation of Red Cross and Red Crescent Societies, 2001. World Disasters Report. Focus on Recovery. International Federation of Red Cross and Red Crescent Societies, Geneva.

Jacobson, J., 1988. Environmental Refugees: A Yardstick of Habitability. WorldWatch Paper 86. WorldWatch Institute, Washington, DC.

Jäger, J., Frühmann, J., et al., 2009. EACH-FOR Synthesis Report. EACH-FOR, Budapest.

Kniveton, D., Schmidt-Verkerk, K., et al., 2008. Climate change and migration: improving methodologies to estimate flows. IOM Migration Research Series, No. 33. IOM, Geneva.

Kolmannskog, V.O., 2008. Future Floods of Refugees. A Comment on Climate Change, Conflict and Forced Migration. Norwegian Refugee Council, Oslo.

Majone, G., 1989. Evidence, Argument, and Persuasion in the Policy Process. Yale University Press, New Haven, CT.

Massey, D.S., Axinn, W., et al., 2007. Environmental Change and Out-Migration: Evidence from Nepal. Research Reports. University of Michigan, Population Studies Center, Ann Arbor.

Milan, S., 2004. Searching for a Place Under the Sun. Inter Press Service, Rieti.

Myers, N., 1993. Environmental refugees in a globally warmed world. BioScience 43 (11), 752-761.

Myers, N., 1997. Environmental refugees. Population and Environment 19 (2), $167-$ 182.

Myers, N., 2002. Environmental refugees: a growing phenomenon of the 21st century. Philosophical Transactions of the Royal Society B 357 (1420), 609-613.

Myers, N., Kent, J., 1995. Environmental Exodus: An Emergent Crisis in the Global Arena. Climate Institute, Washington, DC.

Nicholls, R.J., 2004. Coastal flooding and wetland loss in the 21st century: changes under the SRES climate and socio-economic scenarios. Global Environmental Change 14 (1), 69-86. 
Nicholls, R.J., Marinova, N., et al., 2011. Sea-level rise and its possible impacts given a 'beyond $4{ }^{\circ} \mathrm{C}$ world' in the twenty-first century. Philosophical Transactions of the Royal Society A 369 (1934), 161-181.

Pearce, F. 2011. Searching for the climate refugees. The New Scientist. 2810.

Piguet, E., 2009. Re-embedding the environment into migration theory. In: Conference: Remaking Migration into Migration Theory: Intersections and CrossFertilisations, University of Brighton and University of Sussex.

Piguet, E., 2010. Linking climate change, environmental degradation, and migration: a methodological overview. Wiley Interdisciplinary Reviews: Climate Change 1 (4), 517-524.

Rahmstorf, S., 2010. A new view on sea level rise. Nature Reports 4, 44-45.

Renaud, F., Bogardi, J.J., et al., 2007. Control, Adapt or Flee. How to Face Environmental Migration? InterSecTions, No. 5. United Nations University Institute for Environment and Human Security (UNU-EHS), Bonn.

Sabatier, P.A., 1987. Knowledge, policy-oriented learning, and policy change: an advocacy coalition framework. Science Communication 8 (4), 649-692.
Stern, N., 2007. The Economics of Climate Change. The Stern Review. Cambridge University Press, Cambridge.

Suhrke, A., 1993. Pressure Points: Environmental Degradation, Migration and Conflict. American Academy of Art and Science, Cambridge, MA.

Suhrke, A., 1994. Environmental degradation and population flows. Journal of International Affairs 47 (2), 473-496.

Tolba, M., 1989. Our biological heritage under siege. BioScience 39, 725-728.

United Nations Convention to Combat Desertification, 2010. Frequently Asked Questions. Retrieved 10 June, 2010. From http://unccd.int/library/menu.php?newch $=181$.

Westing, A.H., 1992. Environmental refugees: a growing category of displaced persons. Environmental Conservation 19 (3), 201-207.

Yenotani, M., 2011. Displacement due to Natural Hazard-Induced Disasters. Global Estimates for 2009 and 2010. IDMC \& NRC, Oslo.

Zolberg, A.R., 1989. The next waves: migration theory for a changing world. International Migration Review 23 (3), 403-430. 